\title{
Avaliação do Potencial de Adsorção de Cromo (VI) através da semente da Moringa oleifera
}

\author{
Evaluation of Chromo (VI) Adsorption Potential through the seed of Moringa oleifera \\ Evaluación del Potencial de Adsorción de Cromo (VI) através de la semilla de Moringa oleifera
}

Recebido: 02/02/2021 | Revisado: 06/02/2021 | Aceito: 14/02/2021 | Publicado: 21/02/2021

\author{
Damião Rodrigues de Souza \\ ORCID: https://orcid.org/0000-0003-3961-2947 \\ Escola Técnica Estadual Dr. Celso Giglio, Brasil \\ E-mail: damiao_rodrigues@ @otmail.com \\ Eduarda Marques de Menezes Benedito \\ ORCID: https://orcid.org/0000-0002-2752-2373 \\ Escola Técnica Estadual Dr. Celso Giglio, Brasil \\ E-mail: eduarda.marques.m.benedito@gmail.com \\ João Victor de Paula Sales \\ ORCID: https://orcid.org/ 0000-0002-5441-6808 \\ Escola Técnica Estadual Dr. Celso Giglio, Brasil \\ E-mail: joaosales022@gmail.com \\ Lucas Zanotti da Silva \\ ORCID: https://orcid.org/0000-0001-5629-3605 \\ Escola Técnica Estadual Dr. Celso Giglio, Brasil \\ E-mail: lucaszanotti2015@gmail.com \\ Natalia Souza Silva \\ ORCID: https://orcid.org/0000-0003-1869-5907 \\ Escola Técnica Estadual Dr. Celso Giglio, Brasil \\ E-mail: Atena_natalia@hotmail.com \\ Maira Akemi Casagrande Yamato \\ ORCID: https://orcid.org/0000-0002-7311-563X \\ Escola Técnica Estadual Dr. Celso Giglio, Brasil \\ E-mail: profmaira.yamato@gmail.com \\ Sandro de Miranda Colombo \\ ORCID: https://orcid.org/0000-0002-1485-6542 \\ Escola Técnica Estadual Dr. Celso Giglio, Brasil \\ E-mail: sandro.colombo@etec.sp.gov.br \\ Alessandra Cristina Pedro \\ ORCID: https://orcid.org/0000-0002-2919-8554 \\ Universidade Federal do Paraná, Brasil \\ E-mail: alecristinapedro@yahoo.com.br \\ Melina Aparecida Plastina Cardoso \\ ORCID: https://orcid.org/0000-0002-0669-1469 \\ Universidade Estadual de Maringá, Brasil \\ E-mail: melina_cardoso@msn.com
}

\begin{abstract}
Resumo
Atualmente, diversas indústrias, como mineradoras, galvanoplásticas, curtumes, manufaturas de produtos eletrônicos, entre outras, lançam efluentes contendo metais pesados nos corpos d'água, contaminando-os. Outro fator que contribui para a contaminação das águas são os pesticidas e fertilizantes lançados no solo, que acabam sendo arrastados pelas chuvas até os rios e lagos. A água potável, um recurso básico e indispensável à vida, acaba por ser minimizada por conta do despejo industrial que contém metais pesados como o cromo, o chumbo e o cádmio. A busca por novas opções de tratamento a esses rejeitos torna-se cada vez mais constante e a utilização da moringa oleífera, uma planta de origem indiana que pode ser utilizada como biossorvente, se destaca por suas propriedades coagulantes e floculantes, e por ser um material orgânico de fácil manuseio. O presente trabalho possui por objetivo avaliar o potencial de adsorção de cromo (VI) através da semente da moringa oleífera. Para isso, as sementes foram avaliadas após extração por solvente a quente por Soxhlet, com n-hexano e seca em estufa por 24 horas a $60^{\circ} \mathrm{C}$, metodologia proposta por Costa et al. (2013). Foram preparadas soluções de K2Cr2O7 de concentração 0,01 mol.L-1. As soluções foram mantidas sob agitação magnética por 24 horas com $0,5 \mathrm{~g}$ do material adsorvente, foram filtradas e analisadas por espectrofotometria de UV/VIS, metodologia adaptada de Tavares et al. (2015). O teor médio de lipídios encontrado no pó da semente, semente e casca foi de 30,2\%, 26,7\% e 4,7\%, respectivamente, já o teor médio de umidade foi de $7,1 \%, 6,0 \%$ e $6,8 \%$. Com base no resultado de adsorção, o pó da semente demonstrou potencial para a
\end{abstract}


remoção de $43 \%$ de cromo (VI), enquanto a semente triturada apresentou potencial de remoção de 7,4\% e a casca $12,6 \%$.Incluir o resumo.

Palavras-chave: Metal pesado; Soxhlet; Adsorção; Biossorção; Espectrofotometria de UV/VIS.

\begin{abstract}
Currently several industries such as mining, galvanoplastics, tanneries, electronics manufacturers and others, throw effluents containing heavy metals into the water bodies contaminating them. Another factor that contributes to water contamination are pesticides and fertilizers thrown into the soil, which end up being dragged by rain to rivers and lakes. Drinking water, a basic and indispensable resource for life, has been minimized due to the discharge of industrial effluents containing heavy metals such as chromium, lead and cadmium. The search for new treatment options for these tailings is becoming more and more frequent and the use of moringa oleifera, a Indian plant that can be used as a biosorbent, stands out for its coagulant and flocculant properties and for being an easy-to-handle organic material. The objective of this work is to evaluate the adsorption potential of the moringa oleifera seed, for this the seeds were evaluated after hot solvent extraction by Soxhlet with n-hexane and oven dried for 24 hours at $60^{\circ} \mathrm{C}$, proposed methodology by Costa et al. (2013). $\mathrm{K} 2 \mathrm{Cr} 2 \mathrm{O} 7$ solutions of 0.01 mol.L-1 concentration were prepared and the solutions were kept under magnetic stirring for 24 hours with $0.5 \mathrm{~g}$ of adsorbent material, filtered and analyzed by UV / VIS spectrophotometry, methodology adapted from Tavares et al. al. (2015). The average lipid content found in the seed dust, crushed seed and peel was $30.2 \%, 26.7 \%$ and $4.7 \%$ respectively, while the average moisture content was $7.1 \%, 6.0 \%$ and $6.8 \%$. Based on the adsorption result, the seed dust showed potential for removal of $43 \%$ of chromium (VI), while the crushed seed had a removal potential of $7.4 \%$ and the peel $12.6 \%$.
\end{abstract}

Keywords: Heavy metal; Soxhlet; Adsorption; Biosorption; UV/VIS spectrophotometry.

\title{
Resumen
}

Actualmente, diversas industrias, como empresas mineras, galvanoplastia, curtidurías, fabricantes de productos electrónicos, entre otras, descargan efluentes que contienen metales pesados a los cuerpos de agua, contaminándolos. Otro factor que contribuye a la contaminación de las aguas son los pesticidas y fertilizantes arrojados al suelo, que terminan siendo arrastrados por las lluvias a los ríos y lagos. El agua potable, recurso básico e indispensable para la vida, acaba siendo minimizada debido al vertido industrial que contiene metales pesados como cromo, plomo y cadmio. La búsqueda de nuevas opciones de tratamiento para estos residuos se hace cada vez más constante y el uso del aceite de moringa, una planta de origen indio que se puede utilizar como biosorbente, destaca por sus propiedades coagulantes y floculantes, y por ser un material facil de manejar. El presente trabajo tiene como objetivo evaluar el potencial de adsorción de cromo (VI) a través de la semilla del aceite de moringa. Para ello, las semillas fueron evaluadas luego de extracción por solvente caliente por Soxhlet, con n-hexano y secadas en estufa por 24 horas a $60^{\circ}$ C, metodología propuesta por Costa et al. (2013). Se prepararon soluciones de $\mathrm{K} 2 \mathrm{Cr} 2 \mathrm{O} 7$ con una concentración de 0.01 mol.L-1. Las soluciones se mantuvieron en agitación magnética durante 24 horas con $0,5 \mathrm{~g}$ del material adsorbente, se filtraron y analizaron por espectrofotometría UV / VIS, metodología adaptada de Tavares et al. (2015). El contenido medio de lípidos encontrado en la semilla, la semilla y el polvo de la corteza fue del $30,2 \%, 26,7 \%$ y $4,7 \%$, respectivamente, mientras que el contenido medio de humedad fue del 7,1\%,6,0\% y 6,8\%. Con base en el resultado de la adsorción, el polvo de semilla mostró un potencial de remoción del $43 \%$ de cromo (VI), mientras que la semilla triturada mostró un potencial de remoción del 7.4\% y la cáscara del $12.6 \%$.

Palabras clave: Metal pesado; Soxhlet; Adsorción; Biosorción; Espectrofotometría UV/VIS.

\section{Introdução}

A industrialização de muitas regiões possui como consequência o crescente aumento no despejo de resíduos e efluentes gerados nas indústrias. Os efluentes possuem características como a de ser inerente à composição das matériasprimas, das águas de abastecimento e do processo industrial. Desta forma, a poluição dos recursos hídricos e muitas vezes até mesmo do solo se dá, principalmente, pela negligência no tratamento de efluentes descartados por indústrias como, galvânicas, curtumes, siderúrgicas entre outras (Melo, 2009)

Os metais desempenham funções importantes no metabolismo dos seres vivos. De acordo com Valls e Lorenzo (2002), suas propriedades são essenciais na manutenção do metabolismo celular. O cromo (III), um metal geralmente encontrado no meio ambiente, é essencial para a dieta dos seres vivos, pois é utilizado no metabolismo de proteínas, glicose e lipídios (Matos et al., 2008).

Metais pesados presentes nos recursos hídricos podem afetar o organismo dos seres vivos de duas formas básicas: sendo tóxicos ao organismo ou bioacumulativos. A bioacumulação consiste no aumento progressivo da concentração do metal 
no organismo dos seres, à medida que se avança a cadeia alimentar (Oliveira, 2017).

Segundo Ackerley et al. (2006), o cromo hexavalente é bioacumulativo e tóxico para os seres vivos, e é despejado no meio ambiente em altas concentrações, o que acaba por contaminar o ambiente natural, desde matéria inorgânica à orgânica. Um dos fatores que contribuem para o alto grau de toxidade do cromo (VI) é a relação com sua habilidade de penetrar nas células, diferentemente do cromo (III), que é necessário ao metabolismo dos seres vivos.

A remoção de metais pesados na água, por adsorção com material orgânico e inorgânico, demostra-se um método intrigante e eficaz para a sorção de metais. O material comumente utilizado para a sorção de metais é o carvão ativado, que possui alta eficiência, porém com custo elevado, desse modo, muitas vezes se torna inviável para o processo de tratamento (Dabrowski, 2000).

Segundo Pagnanelli (2003), os materiais orgânicos se tornam atrativos ao processo de adsorção por possuírem grupos funcionais como a lignina, proteínas, hidratos de carbono, entre outros. Esses grupos funcionais favorecem o processo de adsorção, pois formam complexos com íons metálicos em solução.

A adsorção é um fenômeno espontâneo, em que uma substância específica possui propriedade de reter sólidos em sua superfície: “Adsorção é um processo tanto de separação como também de purificação das partículas” (Mota, 2018, p. 20).

O processo de biossorção consiste na adsorção de íons metálicos em adsorventes biodegradáveis, como resíduos agrícolas, que possuem um menor custo comparado aos métodos de tratamento por precipitação química e a utilização do carvão ativado, evitando a formação de lodos biológicos e por possuir a possibilidade de recuperação do metal (Silva \& Oliveira, 2011).

A Moringa oleifera Lamarck é uma planta de origem indiana, encontrada no Brasil, que possui um elevado valor nutricional e medicinal. Após a extração do óleo de suas sementes é possível triturá-las para a obtenção de uma torta que possui ação hipotensiva, adsortiva e antioxidante, podendo ser utilizadas para a purificação de águas que possuem elevado padrão de cor, metais pesados e turbidez (Costa et al., 2013).

Dentre as diversas pesquisas empregadas na utilização das sementes de moringa no tratamento de águas e efluentes, Meneghel (2012) baseou sua pesquisa na utilização das sementes da moringa para adsorção de metais pesados, coagulaçãofloculação-sedimentação de efluentes de indústrias galvânicas; já Paterniani, Mantovani e Sant'anna (2009) utilizaram as sementes da moringa para o tratamento de águas superficiais, contendo chumbo, extraindo das sementes um tipo de coagulante.

Dessa forma, o objetivo deste trabalho foi avaliar o potencial de adsorção de cromo (VI) utilizando as sementes da Moringa oleifera como biossorvente, avaliando o tempo de contato, variação de massa, modo de preparo e realizando a análise das soluções pós-adsorção por espectrofotometria de UV/VIS.

\section{Materiais e Métodos}

Este estudo apresenta-se como sendo quantitativa, pois considera a quantificação dos dados relacionados aos ensaios físico-químicos, de adsorção, de adsorção comparativo e do tratamento do resíduo restante de cromo (VI), que em números, sugerem informações que possam ser analisadas estatisticamente (Prodanov \& Freitas, 2013). Posteriormente, para que se pudesse descrever a relação "causa e efeito" de adsorção de cromo (VI) através da semente da Moringa oleifera, empregou-se a abordagem descritiva, que tem como principal objetivo descrever fenômenos e a complexidade existente entre as variáveis (Pereira et al., 2018).

\subsection{Caracterização Físico-Química}

As metodologias utilizadas para a caracterização físico-química das sementes de Moringa oleífera foram baseadas no 
manual do instituto Adolfo Lutz (2008).

Para a avaliação do teor de umidade, uma cápsula de alumínio foi padronizada em estufa simples a $105^{\circ} \mathrm{C}$ por $1 \mathrm{~h}$, resfriada em dessecador e pesada em balança semi-analítica, modelo Gehaka BK502. Em seguida, cerca de 5g do material pós trituração foi adicionado à cápsula, seco em estufa simples a $60^{\circ} \mathrm{C}$ por $24 \mathrm{~h}$, resfriado em dessecador para posterior pesagem. A análise foi realizada em triplicata, com todas as frações analisadas.

A expressão utilizada para o cálculo do teor de umidade utilizado é representada pela Equação 1:

$$
\text { Umidade } \%=\frac{\mathrm{N} \times 100}{\mathrm{P}} \text { eq.(1) }
$$

Onde:

$\mathbf{N}=$ perda de massa em $\mathrm{g}$

$\mathbf{P}=$ massa da amostra em $\mathrm{g}$

O teor de lipídios do material foi avaliado por meio da extração com n-hexano a quente por soxhlet, com as diferentes frações por 4 horas após a determinação do teor de umidade. Os balões utilizados foram padronizados em estufa simples a $105^{\circ} \mathrm{C}$ por 1 hora para retirada de gorduras que pudessem interferir na obtenção do peso real do balão pré extração. Os balões foram resfriados em dessecador e pesados em balança semi-analítica (Gehaka BK502).

Para a extração nos cartuchos foram adicionados $4 \mathrm{~g}$ de amostra e foram submetidas à extração, após 4 horas foi realizada uma destilação simples para recuperação do solvente e os balões foram novamente padronizados, resfriados e pesados.

A expressão utilizada para o cálculo do teor de lipídios é a mesma definida para o cálculo do teor de umidade, segundo o instituto Adolfo Lutz (2008):

$$
\text { Lipidios totais } \%=\frac{\mathrm{N} \times 100}{\mathrm{P}} \text { eq.(2) }
$$

Onde:

$\mathbf{N}=\mathrm{n}^{\circ}$ de lipídios extraídos em $\mathrm{g}$

$\mathbf{P}=\mathrm{n}^{\circ}$ de g da amostra

\subsection{Preparo do Adsorvente}

As sementes da moringa foram adquiridas na cidade de Sorocaba-SP, Brasil. Inicialmente, as frações da moringa foram divididas em pó da semente, semente triturada e o pericarpo.

As sementes em pó foram obtidas através da trituração em liquidificador convencional, enquanto a semente triturada foi macerada em almofariz. A casca foi separada da semente e triturada também em liquidificador de uso doméstico.

Em seguida, o primeiro grupo de frações foi seco em estufa a $60^{\circ} \mathrm{C}$ por 24 horas, desengordurado por extração em soxhlet a quente com n-hexano $\left(\mathrm{C}_{6} \mathrm{H}_{14}\right)$ por 4 horas, com $4 \mathrm{~g}$ de amostra e, posteriormente, a torta foi seca em estufa a $60^{\circ} \mathrm{C}$ por 24 horas para total evaporação do solvente (Meneghel, 2012).

\subsection{Obtenção da Curva de Calibração}

Foram preparadas quatro soluções de concentração conhecida de $0,05,0,1,0,25$ e 0,5 mmol. $\mathrm{L}^{-1}$ de dicromato de 
potássio previamente padronizado em estufa a $100^{\circ} \mathrm{C}$ por 2 horas. As soluções foram lidas em espectrofotômetro de UV/VIS (Nova instrument NI 1800 UV), no comprimento de onda de 400 a 750nm em duplicata, e com o valor de absorbância obtido determinou-se a curva de calibração (Silva et al., 2018).

\subsection{Ensaios de Adsorção}

As condições avaliadas foram de 24 horas de tempo de contato entre o material adsorvente e a solução, $0,5 \mathrm{~g}$ de material pós extração e o sistema foi mantido sob agitação magnética constante.

O material foi submetido à agitação magnética com $50 \mathrm{~mL}$ de uma solução de dicromato de potássio a 10 mmol.L-1, conforme a Figura 1. Após o tempo estabelecido, a solução foi filtrada e centrifugada a 2400rpm em centrífuga (Fanem 206BL) durante 5 minutos. Após, foi realizada análise da concentração da solução pós-adsorção por espectrofotômetro de UV/VIS e, posteriormente, armazenada (Araújo, 2009).

Figura 1 - Processo de adsorção sob agitação magnética.

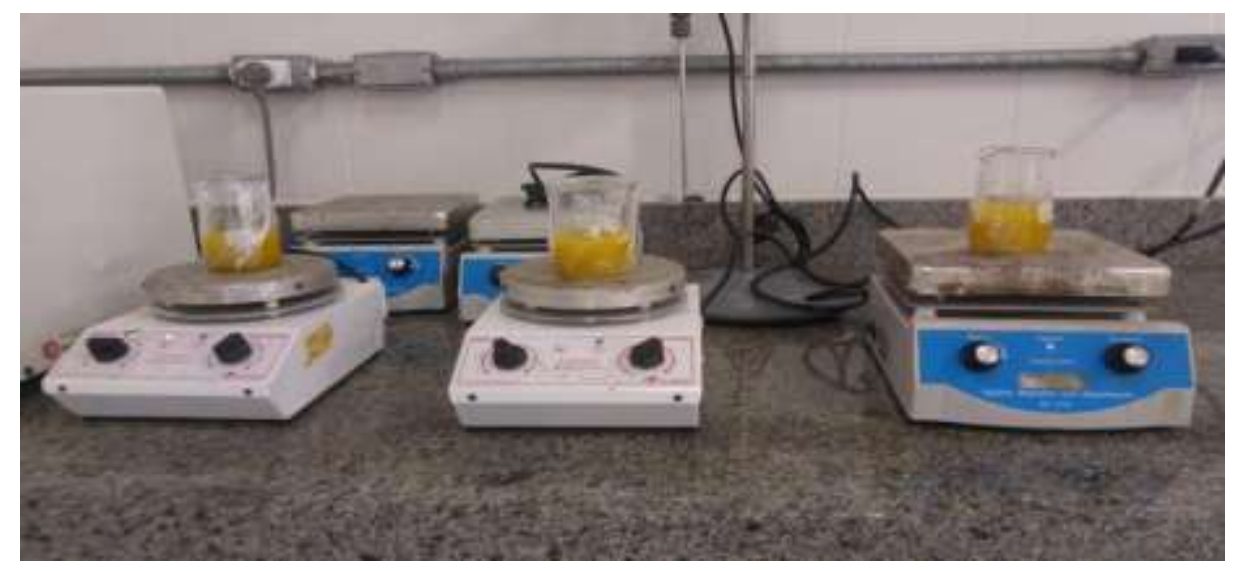

Fonte: Autores (2019).

Para o cálculo da concentração final de íons dicromato livres na solução pós-adsorção, a equação dada por:

$\boldsymbol{Y}=\mathbf{C o} \times \mathbf{X}+\mathbf{C e}$ eq. (3)

Onde $\boldsymbol{Y}$ simboliza a absorbância medida nas análises, $\mathbf{C o}$ o coeficiente angular, $\mathbf{X}$ a concentração em mmol. $\mathrm{L}^{-1} \mathrm{e} \mathbf{C e}$ o coeficiente linear.

\subsection{Ensaio de Adsorção Comparativo}

Foram realizadas análises conforme os parâmetros definidos como ótimos por Tavares et al. (2015) para o tratamento de águas contendo chumbo, como 30 minutos de tempo de contato entre o material adsorvente e a solução e $2 \mathrm{~g}$ de material lavado com água ultrapura por 45 minutos. O sistema foi mantido sempre sob agitação magnética.

O método utilizado para o ensaio de adsorção comparativo segue o mesmo procedimento do item 2.4 deste artigo.

\subsection{Tratamento do Resíduo Restante de Cromo (VI)}

Inicialmente, o dicromato de potássio foi reduzido a cromo (III) com agente redutor tiossulfato de sódio e ácido sulfúrico a 50\%, na proporção de massa segundo a reação descrita por Vogel (1981):

$2 \mathrm{Cr}_{2} \mathrm{O}_{7}^{-2}+3 \mathrm{H}_{2} \mathrm{~S}+10 \mathrm{H}^{+} \rightarrow 2 \mathrm{Cr}^{+2}+2 \mathrm{~S} \downarrow+8 \mathrm{H}_{2} \mathrm{O}$ 
A solução pós redução foi filtrada para a separação do enxofre que foi precipitado. O enxofre foi descartado e, para a precipitação do cromo (III), o pH da solução foi ajustado com hidróxido de sódio $(\mathrm{NaOH})$, utilizando pHmetro digital, modelo PG 1800, até pH 9,5, segundo a metodologia proposta por Sari et al. (2015).

O precipitado formado foi separado do sobrenadante por filtração. O precipitado foi calcinado em mufla (UP BRASIL $2000^{\circ} \mathrm{C}$ simples) a $600^{\circ} \mathrm{C}$ por 2 horas, em cadinho de porcelana, e a solução foi novamente ajustada a pH 9,5 para verificar se havia presença de cromo (III). Quando não houve mais precipitado, a solução foi neutralizada e descartada.

\section{Resultados e Discussão}

\subsection{Caracterização Físico-Química}

Os resultados obtidos da caracterização físico-química das frações da moringa: pó da semente, semente triturada e casca, encontram-se na Tabela 1.

Tabela 1 - Caracterização físico-química das frações da semente em porcentagem.

\begin{tabular}{ccc}
\hline Amostra & Lipídios totais (\%) & Umidade (\%) \\
\hline Pó da semente & 30,2 & 7,1 \\
Semente triturada & 26,9 & 6,0 \\
Casca & 4,7 & 6,8 \\
\hline
\end{tabular}

Fonte: Autores (2019).

Os resultados obtidos através da caracterização físico-química das frações da semente da moringa foram: 7,1\% de umidade e 30,2\% de lipídios totais para o pó da semente; $6,0 \%$ de umidade e $26,9 \%$ de lipídios totais para a semente triturada e $6,8 \%$ de umidade e $4,7 \%$ de lipídios totais para a casca.

Comparando-os às análises feitas por Oliveira et al. (2009), onde a semente possui 3,27\% de umidade e 22,7\% de lipídios, o pó da semente variou mais de 3,8\% no teor de umidade e 7,5\% para o teor de lipídios, a semente triturada variou $2,73 \%$ no teor de umidade e $4,7 \%$ no teor de lipídios e a casca variou 3,5\% no teor de umidade. O teor de umidade variou para menos de 17,9\% do resultado observado pelos autores.

Comparando os resultados com a resolução das análises feitas por Passos et al. (2012), os dados de umidade se encontram abaixo da média, variando em menos de 45,6\% em relação à amostra in natura, onde o resultado é de 52,60\%, e em relação à amostra seca 2,67\% se encontra com maior variação, divergindo para mais do que 5,3\%, o que pode evidenciar que as sementes utilizadas já estavam em processo de secagem natural, devido ao seu longo período de armazenamento.

Em comparativo aos dados do teor de lipídios, o autor obteve resultados de 2,39\% para a semente in natura e 17,37\% para a amostra seca, dados esses que, em relação aos obtidos neste trabalho, estão cerca de 18,21\% abaixo em relação à amostra in natura e 3,23\% para a amostra seca, porém, ao observar os resultados de lipídios totais para a casca da semente, $4,7 \%$ demostra o resultado de 2,3\% acima da amostra in natura, mas 12,67\% abaixo da amostra seca. Esses resultados indicam que a amostra pode variar em relação ao período de colhimento, região na qual é plantada, maneira de armazenamento e processo de secagem natural.

\subsection{Preparo do Adsorvente}

Após a separação das frações e sua posterior trituração, o material adsorvente denominado pó da semente obteve uma característica de granulometria pequena e inodora, a semente triturada obteve uma granulometria maior com um odor característico de gramado e a casca em pó se assemelhou ao pó da semente. Na Figura 2 pode-se observar as frações, onde: A é 
o pó da semente, $\mathbf{B}$ a semente triturada e $\mathbf{C}$ a casca.

Figura 2 - Pó da semente (A), semente (B), pó da casca (C).

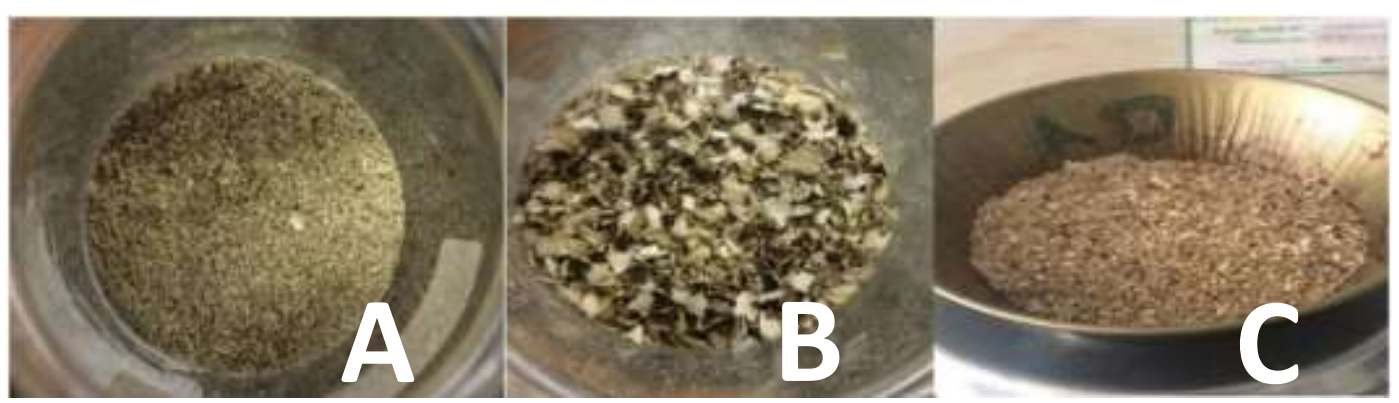

Fonte: Autores (2019).

\subsection{Curva de Calibração}

A curva analítica obtida apresentou o coeficiente angular com o valor de 1,3107, coeficiente linear de 0,1312 e uma confiabilidade de $99,7 \%$, o que pode ser observado no Gráfico 1 e, com a curva de calibração, o comprimento de onda adequado para a identificação da concentração de íons dicromato livre foi de 400nm.

Gráfico 1 - Curva de calibração do dicromato de potássio em mmol.L $\mathrm{L}^{-1}$

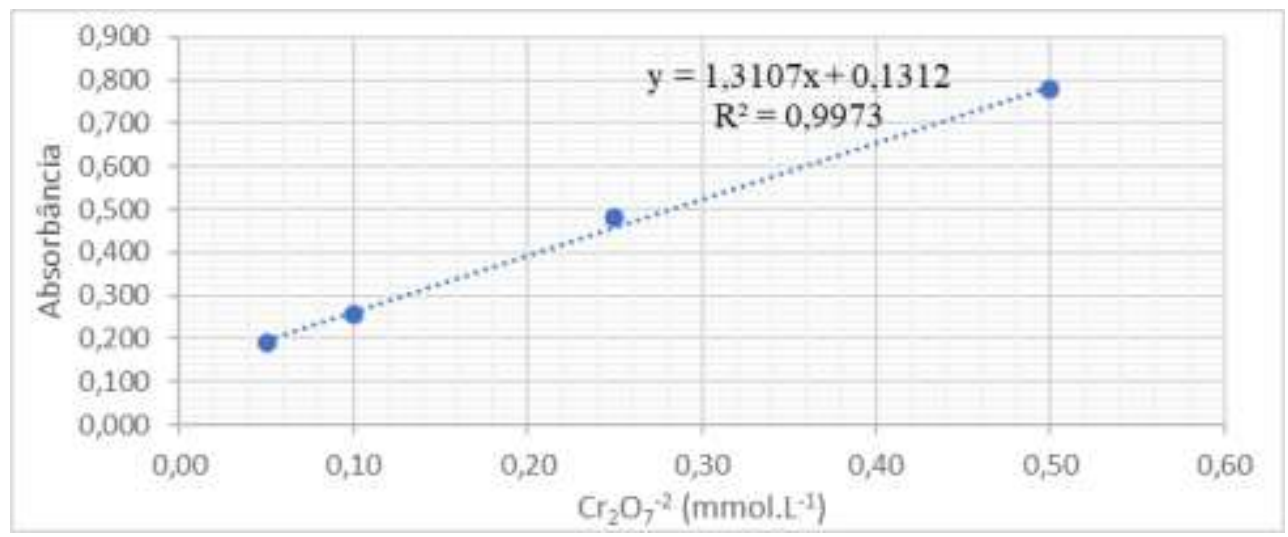

Fonte: Autores (2019).

\subsection{Ensaio de Adsorção}

Através da Tabela 2, pode-se observar os percentuais de adsorção de cada uma das frações da moringa, pó da semente, semente triturada e casca, analisadas.

Tabela 2 - Concentração e absorbância das amostras pós-adsorção.

\begin{tabular}{cccc}
\hline Amostras & Absorbância & $\mathbf{C r}_{2} \mathbf{O}_{7^{-2}}(\mathbf{m m o l} / \mathbf{L})$ livre & $\mathbf{C r}_{2} \mathbf{O}_{7}^{-2}(\boldsymbol{\%})$ adsorvido \\
\hline Pó da semente & 0,913 & 5,964 & $43,0 \% \pm 3$ \\
Semente triturada & 0,7435 & 9,343 & $7,4 \% \pm 1$ \\
Casca & 0,7085 & 8,808 & $12,6 \% \pm 1$ \\
\hline
\end{tabular}

Fonte: Autores (2019).

É possível observar que houve uma relativa redução na concentração da solução inicial de dicromato, entretanto, nota- 
se que a fração que obteve um maior índice de adsorção foi o pó da semente, que adsorveu em média 43\% do metal.

O resultado de $43 \%$ de adsorção obtido no presente trabalho assemelhou-se ao resultado obtido por Meneghel (2012), em que houve a remoção de 40,48\% de cromo III em 120 minutos, com soluções simuladas utilizando a torta de Moringa oleifera, porém, os demais resultados não alcançaram um percentual de remoção de cromo (VI) maior do que 30\%, variando para menos de $33,08 \%$ com a semente triturada e $27,9 \%$ com a casca, resultados estes que podem ser influenciados pelo tipo de preparo dos materiais, o tempo de contato, $\mathrm{pH}$ e superfície de contato.

Em comparação ao artigo de Goettems (2019), no qual o autor utilizou da microalga Scenedesmus SP para a adsorção de cromo (VI), a biomassa viva adsorveu $35,21 \%$ e a biomassa seca 18,02\% em 24 horas. Os resultados obtidos neste trabalho variam em relação aos do autor, onde: o pó da semente de moringa que adsorveu $43 \%$ variou cerca de 7,8\% para mais que o resultado obtido pelo autor ao utilizar a biomassa viva, e em relação à biomassa seca variou para mais do que 24,98\%.

Em comparativo às outras frações analisadas, os dados do autor se encontram maiores, tanto para a biomassa viva quanto para a biomassa seca, variando para mais que $22 \%$ e $8 \%$, respectivamente, para a semente triturada e a casca.

A diferença entre os resultados pode ser referente à diferença da natureza entre os materiais adsorventes, as concentrações das soluções de cromo (VI), a interação do metal com o material, sítios disponíveis e o modo de realização da adsorção já que, no caso do autor, as microalgas cresceram juntamente à solução de cromo (VI).

\subsection{Ensaio de Adsorção Comparativo}

Utilizando os parâmetros estabelecidos como ótimos para a adsorção de chumbo por Tavares et al. (2015), onde o tempo de contato ótimo foi de 30 minutos utilizando $2 \mathrm{~g}$ de adsorvente lavado com água ultrapura por 40 minutos. Na Tabela 3 seguem os resultados das concentrações de íons dicromato livre, para as frações da moringa, pós da semnente, semente triturada e casca, pós adsorção com o método comparativo citado anteriormente.

Tabela 3 - Concentração de íons dicromato livre pós adsorção com método comparativo.

\begin{tabular}{cc}
\hline Amostra & $\mathrm{Cr}_{2} \mathbf{O}_{7}^{-2}(\%)$ adsorvido \\
\hline Pó da semente & $26 \% \pm 3$ \\
Semente triturada & $13 \% \pm 1$ \\
Casca & $29 \% \pm 1$ \\
\hline
\end{tabular}

Fonte: Autores (2019).

Ao analisar os resultados obtidos, nota-se que a fração que demonstrou maior eficiência para adsorção de cromo (VI) com os parâmetros definidos por Tavares et al. (2015) foi a casca, que adsorveu cerca de $29 \%$. No artigo dos autores, a moringa chegou a adsorver cerca de $96 \%$ de chumbo com concentração de $4 \mathrm{mg} . \mathrm{L}^{-1}$, o que pode evidenciar que os parâmetros ótimos de adsorção de chumbo propostos pelos autores não se encaixam na adsorção de cromo (VI), a menos que haja o controle de $\mathrm{pH}$ e temperatura.

\subsection{Tratamento do Resíduo Restante de Cromo (VI)}

Para o descarte correto da solução de cromo (VI), a mesma deve possuir concentração de $0,1 \mathrm{mg} . \mathrm{L}^{-1}$, parâmetro estabelecido pela legislação brasileira (Brasil, 2011). As soluções que foram armazenadas após adsorção possuíam concentrações superiores a $0,1 \mathrm{mg} . \mathrm{L}^{-1}$, logo, necessitaram de um tratamento adicional, o qual foi realizado de forma qualitativa.

Após a adição de tiossulfato de sódio $\left(\mathrm{Na}_{2} \mathrm{~S}_{2} \mathrm{O}_{3}\right)$ e ácido sulfúrico $\left(\mathrm{H}_{2} \mathrm{SO}_{4}\right)$, a coloração da solução passou de amarelo para verde, indicando sua redução para cromo (III), como pode ser observado na Figura 3. 
Figura 3 - Solução de dicromato pós-adsorção (A) e solução de cromo III reduzida (B).

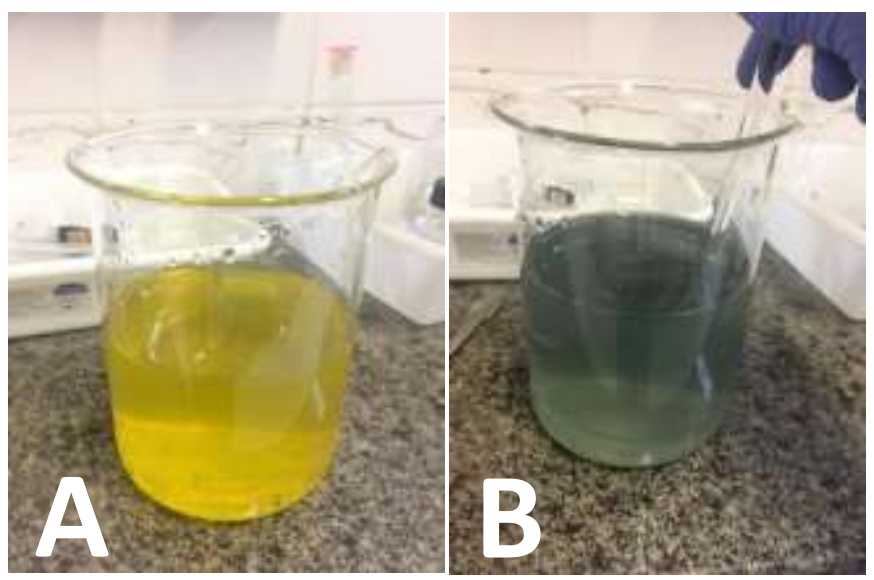

Fonte: Autores (2019).

Com o ajuste de $\mathrm{pH}$ utilizando hidróxido de sódio $(\mathrm{NaOH})$ houve a formação de um precipitado gelatinoso e verde, referente ao hidróxido de cromo (III). Após a filtração, o sobrenadante demonstrou-se translúcido. Conforme a Figura 4, o sobrenadante foi descartado e o filtrado calcinado e armazenado para reutilização.

Figura 4 - Formação do precipitado gelatinoso (A) e solução após tratamento (B).

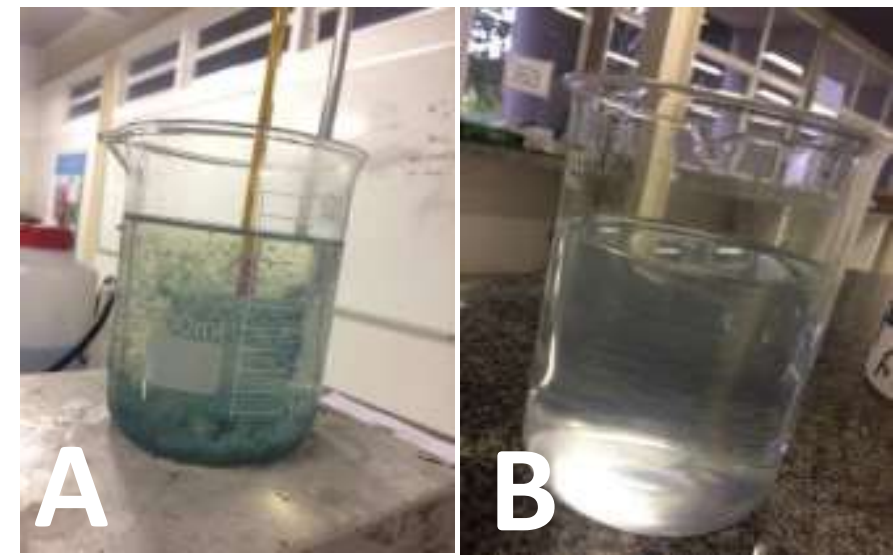

Fonte: Autores (2019).

\section{Conclusão}

Com base nos resultados obtidos neste trabalho, pode-se concluir que as sementes da moringa utilizadas como biossorvente possuem potencial na adsorção de cromo (VI) em suas três frações estudadas (pó da semente, semente triturada e o pericarpo). O tempo de contato realizado nos ensaios de 24 horas com 0,5 g do biossorvente em $50 \mathrm{~mL}$ de cromo (VI) foi satisfatório. Entre as frações estudadas, o pó da semente foi a que obteve maior efetividade, resultando em $43 \%$ na adsorção de cromo hexavalente.

Analisando os resultados deste artigo comparativamente com os resultados de outros autores, nos quais a moringa chegou a adsorver cerca de $96 \%$ de chumbo com concentração de $4 \mathrm{mg} . \mathrm{L}^{-1}$, conclui-se que os parâmetros ótimos de adsorção de chumbo propostos pelos autores não se encaixam na adsorção de cromo (VI).

Através dos resultados observados neste trabalho, podemos indicar a moringa para o pré-tratamento de resíduos de laboratório, por possuir a capacidade de recuperação do metal. Por fim, pode-se concluir que a semente da Moringa oleífera se mostrou uma alternativa atrativa na remoção cromo (VI), tanto do ponto de vista de eficiência quanto em relação ao seu baixo 
custo.

Sugere-se, como trabalhos futuros, o estudo mais aprofundado com relação ao $\mathrm{pH}$ e também à temperatura utilizadas no processo, para que os resultados possam ser ainda mais satisfatórios ou mais eficientes, considerando-se os custos e o tempo de aplicação. Além disso, acredita-se que haja potencialidade no estudo das cinzas produzidas a partir da incineração deste material, visto que se estudada, esta cinza pode servir de base tanto para novas aplicações como para síntese do cromo (VI) para outras finalidades.

\section{Referências}

Ackerley, D. F., Barak, Y., Lynch, S. V., Curtin, J., \& Matin, A. (2006). Effect of Chromate Stress on Escherichia coli K-12. Journal of Bacteriology, 9(188), 3371-3381.

Araújo, C. S. T. (2009). Desenvolvimento de metodologia analítica para extração e pre-concentração de Ag(I) utilizando a moringa oleifera Lam. 2008.215 f. Tese (Doutorado) - Curso de Química, Universidade Federal de Uberlândia, Uberlândia.

Brasil. Conselho Nacional do Meio Ambiente. Resolução no 430, de 13 de maio de 2011. (2011). Diário Oficial da União, Brasília. http://www2.mma.gov.br/port/conama/legiabre.cfm?codlegi=646.

Costa, E. C., Barbosa, C. A. E. S., Garcia, H. L., \& Garcia, C. A. B. (2013). Pó da semente da Moringa oleífera como adsorvente de poluentes metálicos. Scientia Plena, 9(10), 1-9.

Goettems, A. M. V. (2019). Biossorção do cromo trivalente e hexavalente proveniente do curtume utilizando a microalga Scenedesmus sp. $2019.76 \mathrm{f}$. Dissertação (Mestrado) - Curso de Ciências Ambientais, Universidade Estadual do Oeste do Paraná, Toledo.

Instituto Adolfo Lutz. (2008). Normas Analíticas do Instituto Adolfo Lutz: Métodos físicoquímicos para análises de alimentos. (4), 1-1020. Recuperado em 15 novembro, 2019, de: https://wp.ufpel.edu.br/nutricaobromatologia/files/2013/07/NormasADOLFOLUTZ.pdf.

Matos, W. O., Nobrega, J. A., Souza, G. B., \& Nogueira, A. R. A. (2008). Especiação redox de cromo em solo acidentalmente contaminado com solução sulfocrômica. Química Nova, 31(6), 1450-1454.

Melo, C. R. (2009). Síntese de zeólita tipo 5A a partir de capim para adsorção de metais pesados de soluções aquosas. 2009.89 f. Dissertação (pósgraduação) - curso de engenharia, Universidade Federal de Santa Catarina, Florianópolis.

Meneghel, A. P. (2012). Remediação de águas contaminados com metais pesados (Cd, Pb e Cr) utilizando torta de semente da moringa oleífera LAM como adsorvente. 2012. 167 f. Dissertação (Mestrado) - Curso de agronomia, Universidade Estadual do Oeste do Paraná, Paraná.

Mota, A. L. F. (2018). Uso da vermiculita na adsorção do corante vermelho reativo bf - 4 b e do óleo presente em água produzida sintética. $2018.46 \mathrm{f}$. Monografia (Especialização) - Curso de Engenharia de Petróleo, Universidade Federal do Semiárido, Mossoró.

Oliveira, I. C., Teixeira, E. M. B., Gonçalves, C. A. A., \& Pereira, L. A. (2009). Avaliação centesimal da semente de moringa oleifera lam. 2009. 4 f. TCC (Graduação) - Curso de Técnico em Alimentos e Laticínios, Campus Uberlândia, Centro IFTM, Uberlândia.

Oliveira, L. T. (2017). Estudo da utilização de Microalgas para a retenção de chumbo em águas residuárias. 2017.47 f. Monografia (Especialização) - Curso de Engenharia Química, Universidade Federal do Rio Grande do Norte, Natal-RN.

Pagananelli, F., Mainelli, S., Veglio, F., \& Toro, L. (2003). Heavy metal removal by olive pomace: biosorbent characterization and equilibrium modeling. Chem. Eng. Sci, 58, 4709-4717.

Passos, R. M., Santos, D. M. C., Santos, B. S., Souza, D. C. L., Santos, J. A. B., \& Silva, G. F. (2012). Qualidade pós-colheita da moringa (moringa oleifera lam) utilizada na forma in natura e seca. Revista Geintec Gestão, inovação e tecnologias, 3(1), 113-120.

Paterniani, J. E. S., Mantovani, M. C., \& Sant'anna, M. R. (2009). Uso de sementes de Moringa oleífera para tratamento de águas superficiais. Revista Brasileira de Engenharia Agrícola e Ambiental, 13(6), 765-771.

Pereira, A. S., Shitsuka, D. M., Parreira, F. J., \& Shitsuka, R. (2018). Metodologia da pesquisa científica. https://repositorio.ufsm.br/bitstream/handle/ 1/15824/Lic_Computacao_Metodologia-Pesquisa-Cientifica.pdf?sequence=1.

Prodanov, C. C., \& Freitas, E. C. (2013). Metodologia do trabalho científico (2a ed.). Feevale.

Santana, P. M. A. (2017). Uso da moringa oleifera lam. como biossorvente de cádmio em águas. 2017.62 f. Dissertação (mestrado) - Curso de engenharia, desenvolvimento de processos ambientais, Universidade Católica de Pernambuco, Recife.

Silva, D. G., Silva, F. M., Holanda, J. V. S., \& Teodoro, M. C. (2018). Remoção de cromo hexavalente de resíduos de laboratório da ETEC Dr. Celso Giglio através de adsorção física utilizando carvão ativado. 2018. 33 f. TCC - Curso de Técnico em Química, ETEC Dr. Celso Giglio, Osasco.

Silva, R. C. O., \& Oliveira, R. (2011). Biossorção de cromo (VI) utilizando cascas de jabuticaba. 2011.36 f. TCC (Graduação) - Curso de Química, Universidade Tecnológica Federal do Paraná, Pato Branco.

Tavares, F. O., Pinto, L. A. D. M., Santos, T. R. T., Vieira, M. F., Bergamasco, R., \& Vieira, A. M. S. (2015). Avaliação do uso da Moringa oleífera como biossorvente na remoção de chumbo em águas contaminadas. Blucher Chemical Engineering Proceedings, 2 (1), $1084-1091$. 
Research, Society and Development, v. 10, n. 2, e40610212591, 2021

(CC BY 4.0) | ISSN 2525-3409 | DOI: http://dx.doi.org/10.33448/rsd-v10i2.12591

Valls, M., \& Lorenzo, V. (2002). Exploiting the genetic and biochemical capacities of bacteria for remediation of heavy metal pollution. FEMS Microbiology Reviews, 26, 327-338.

Vogel, A. I. (1981). Química analítica qualitativa. (5). Mestre JOU. 